\title{
Aproximaciones transdisciplinarias a Un soplo de vida, pulsaciones de Clarice Lispector
}

\author{
Transdisciplinary approximations towards \\ Clarice Lispector's Un soplo de vida, pulsaciones
}

\author{
Niklas Bornhauser Neuber \\ Valentina Bravo Pelizzola \\ Universidad Andrés Bello. Santiago, Chile. \\ nbornhauser@unab.cl, valepelizzola@gmail.com
}

\section{RESUMEN}

El trabajo presente aborda, desde un punto de vista multidisciplinario, la obra literaria de la escritora brasilera Clarice Lispector, titulada Un soplo de vida, pulsaciones. Su propósito consiste en poner a dialogar la literatura y el psicoanálisis, sin suponer la primacía de una práctica discursiva sobre otra. La lectura en cuestión está guiada por la hipótesis de que es posible desprender del texto cierta concepción de sujeto, que emerge como resultado del atravesamiento del lenguaje conceptualizado por Jacques Lacan, vinculada estrechamente con la determinación significante. Al situarse más allá de las investigaciones psicobiográficas clásicas, se entreabre una vía productiva para la discusión transversal, convocando un repertorio conceptual heterogéneo y plural.

Palabras claves: Lectura, sujeto, psicoanálisis, autor, texto.

\section{ABSTRACT}

The present paper approaches, from a multidisciplinary perspective, to the literary auvre of the Brazilian writer Clarice Lispector, entitled Un soplo de vida, pulsaciones. 
Its purpose is to establish a dialogue between literature and psychoanalysis, without assuming the primacy of one discursive practice over another. The reading in question is guided by the assumption that the text can it is possible to detach certain conception of subject, closely linked to the significant determination, which emerges as a result of the traversing by language conceptualized by Jacques Lacan. Placing itself beyond the classical psychobiographical research, it opens a productive avenue for the transversal discussion, convening a diverse and plural conceptual repertoire.

Keywords: Reading, subject, psychoanalysis, author, text.

Recibido: 18-01-2010. Aceptado: 25-04-2010.

\section{INTRODUCCIÓN}

C6 To se interpreta al artista a través de su obra, sino que es el objeto de 1 arte el que interpreta al espectador al funcionar como objeto que causa su deseo porque captura su mirada pero sobre todo porque le hace hablar" (Ponce, 2006: 150).

El presente trabajo, tal como sugiere la cita introductoria, está guiado por la siguiente premisa: el texto literario, en vez de pre-existir, de modo autónomo, en un espacio aséptico y soberano ${ }^{1}$, se configura como objeto que causa el deseo, que "hace hablar". De este modo, nuestra lectura de Un soplo de vida, a diferencia de ciertas aproximaciones psicobiográficas clásicas (Erikson, 1958, 1975; Baron y Pletsch, 1985; Ciardiello, 1985), no pretende descubrir lo que el autor -la Lispector, en este caso- habría intentado transmitir, pero no alcanzó a decir, acaso pretendiendo, a través de dicho ejercicio interpretativo, develar ciertas verdades ocultas, reduciendo el texto a expresión sintomática de un psiquismo conflictuado.

Nuestra intención, en ese sentido, no es apresar en la obra algo velado, secreto, que defina la verdad del Otro en tanto portador de una certeza irrefutable, sino, más bien, en relación a la lectura propuesta, nos interesa

\footnotetext{
${ }^{1}$ Por ende, se cuestiona la presunta objetividad del texto, puesto que su significado, más que desprenderse naturalmente y de modo comprensible de suyo, de él mismo -o de la intención atribuida al escritor-, depende del lector. Él o los significados en cuestión se producen, se desvanecen a través de los vacíos, huecos y sobresaltos que irá produciendo el texto, ya que éste "no es un lleno, sino un espacio globular, atacado por intersticios, blancos, fisuras, saltos, elipsis, silencios que ponen al lector en la obligación de realizar una serie de operaciones, no para restituir una unidad que nunca ha existido, sino para construir un sentido que no yace absolutamente inerte en el texto" (Sarlo, 1985: 8).
} 
postular una idea de verdad, que tiene que ver, en tanto posibles puntos de plusvalía, con el tiempo, la propia experiencia y, en este caso, con la matriz epistemológica en la que se arraiga dicho proceso. La crítica y lectura que puedan ejercerse, más que un escrutinio de los bajos fondos, una búsqueda de ciertas verdades recónditas, atesoradas en las presuntas profundidades del psiquismo, es un acto de creación e implica asumir la destitución del lector desde un lugar autorreferente y egocéntrico. Aquel descentramiento del lector implica, a la vez, renunciar a toda concepción de subconsciente, $U n$ terbewusstsein, basada en una representación topográfica simple que asocie lo subconsciente con lo profundo, lo recóndito y subterráneo. Significa, en cambio, asumir el hecho que lo inconsciente, das Unbewusste, está estructurado como un lenguaje y, como consecuencia de la primacía del significante, no mantiene una relación privilegiada con las profundidades.

Es por ello que descartamos el abordaje psicobiográfico tradicional, que recurre a determinadas características biográficas de la vida del autor, intentando dilucidar cómo estos aspectos -los que, sin duda, ejercen su influencia- se plasmarán en el texto. En lugar de esta vía, por muy fecunda que resulte, apostamos a los resultados de una interpretación, que no deposite en Lispector -o en su psiquismo, respectivamente- el sentido y la fuente última de la obra. Ello implica, de entrada, hacerse cargo del carácter irreductiblemente po(i)ético de toda lectura, asumiendo que la lectura construida será una entre muchas otras lecturas posibles. En este sentido, se intentará poner de relieve la plasticidad del material verbal y escrito, en tanto el significante aleja a la interpretación de la arbitrariedad de las significaciones convencionales y permite abordar la obra situando a la palabra como elemento fundamental, constitutivo y constituyente del sujeto que ésta misma genera. La aproximación que quisiéramos promover sería una forma de lectura que considera al texto no como un discurso de un autor sobre o acerca del inconsciente -o del inconsciente sobre el autor-, sino como un lugar en el cual se produce lo inconsciente como efecto, en tanto fenómeno discursivo $\mathrm{y}$ transindividual.

De esta forma, el énfasis de nuestra lectura estará puesto en el significante, el que enfrentará al sujeto con su desconocimiento y su extranjería interior (inneres Ausland) (Freud, 1933 [1932]) al ser asaltado por una producción que le pertenece, pero que, sin embargo, no reconoce como propia. Dicho desconocimiento lo lleva a la fractura y la duda, enfrentándolo con la evidencia de que lo más íntimo y personal sería, al mismo tiempo, lo más ajeno a él (Freud, 1919). El sujeto, resultado preliminar e incierto de dicho abordaje, carece de toda esencialidad ontológica habitualmente atribuida al 
llamado sujeto moderno, y se reconoce como siendo en relación a Otro, al Otro del lenguaje y sus determinaciones. Se trata, por ende, de un sujeto que no se cierra con respecto a sí mismo, quedando así en cierto desfase con su propio ser y por lo tanto, descentrado de sí mismo: esa identidad que se pretende unificar, eso que intenta responderse y obturarse en y a través del Otro, caerá y se evidenciará la sobredeterminación que lo Simbólico ejerce sobre este intento.

Consiguientemente, la pregunta que guiará nuestra lectura de la obra no pretende dar una respuesta acabada o conclusiva con respecto al eventual "sentido" del texto, sino encaminará una posible interpretación, un eje rector para articular una reflexión en torno al correspondiente concepto de sujeto que puede leerse a través de la misma.

\section{UNA ESCRITURA EN LOS CONFINES DE LA MODERNIDAD}

Clarice Lispector (Tchetchelnik, Ucrania, 1920 - Río de Janeiro, Brasil, 1977) es considerada una de las más importantes escritoras brasileñas del siglo XX; su literatura, más que seguir ciertos principios canónicos sobre cómo contar una historia o relatar acontecimientos externos de una red de personajes definidos, apunta a los monólogos interiores, las percepciones y sensaciones sobre lo cotidiano y sus detalles, que lo llevan a traspasar sus propios límites y develan lo absurdo en él.

Pese a lograr una prosa aguda y acentuadamente intelectual, el proceso escritural de Lispector, como ella misma señala, tiene que ver más con intuiciones sobre acontecimientos triviales, que luego derivan en ideas que abandonan lo inmediato para sobrepasar o cuestionarlo. En lugar de una narración única, que apuesta al desarrollo de una unidad esencial, propone una multiplicidad de historias diferentes y narraciones locales que no se unifican en un relato abarcador y se resisten a la formalización.

En la obra de Lispector, la percepción de la realidad es evasiva e inasible, por cuanto se duda de una verdad eterna e inmutable, existente ahí afuera, posible de ser aprehendida por el sujeto. Los objetos, las personas y sus sentimientos constituyen un misterio y sólo se captan retazos de su forma, pero jamás su esencia. Ya no es posible pensar la realidad en torno a un principio supremo, trascendente: "Dios muere en la medida en que el saber ya no tiene necesidad de llegar a las causas últimas, en que el hombre no necesita ya creerse con un alma inmortal" (Vattimo, 1994: 27) y, por lo tanto, cae la noción de una historia universal, dando paso a una pluralidad de realidades 
y visiones de mundo.

Al cuestionarse la validez incuestionable de los puntos fijos de referencia, se diversifican las posibilidades de elección individual, por lo que surge una nueva noción de subjetividad, disuelta en identidades provisorias y vulnerables y, por lo mismo, declinables y abiertas. Así, la realidad, en lugar de una verdad única incuestionable, sería, según Vattimo, "el resultado del entrecruzarse, del contaminarse de las múltiples imágenes, interpretaciones y reconstrucciones que compiten entre sî" (1990: 87). De acuerdo a ello, la noción que Lispector tiene del proceso de escritura, coincide con el debilitamiento, anteriormente señalado, de un sentido único: "El proceso de escribir está hecho de errores [...] No conduce a nada y de repente aquello que se pensó que era 'nada' era el propio temible contacto con la textura de vivir. $Y$ ese instante de reconocimiento, ese sumergirse anónimo en la textura anónima, ese instante de reconocimiento (igual a una revelación), necesita ser recibido con la mayor inocencia" (Lispector, 2007: 81). Lejos de concebir una escritura teleológica, que promueve una sola verdad, un solo sentido, Lispector prefiere instalarse en la interrogante, la incertidumbre y hallarse en lo inhallable de sí y del resto, material huidizo que dispone a la palabra a una permanente búsqueda ${ }^{2}$.

Asimismo, se plantea un cuestionamiento de la correspondencia entre realidad y palabra, pues lo representado nunca es la cosa real, al tiempo que sólo es posible lidiar con la realidad mediante la palabra. Paradójicamente, los signos codifican esta realidad, la simulan y reproducen para aprehenderla, pero es justamente bajo esta codificación que se vuelve inasible: "Escribo con palabras que ocultan otras, las verdaderas. Es que las verdaderas no pueden denominarse. Aunque no sepa cuáles son las 'verdaderas palabras', estoy siempre aludiendo a ellas" (Lispector, 1999: 71). La palabra utilizada se vuelve insuficiente, no se encuentra aquella que realmente traduzca el pensamiento, pero, aún así, es la única herramienta posible para articular incluso la no-palabra, el silencio, e implantarse como una toma de poder con respecto a lo circundante.

A partir de ello, su escritura deriva en la deconstrucción del sentido y la identidad, así como todos los constituyentes del texto -lengua, argumento, sujeto-, pues no sólo pondrá en duda la subjetividad de los protagonistas,

\footnotetext{
${ }^{2}$ Situada en este contexto, la obra de Lispector transmite una percepción peculiar del mundo por medio de un lenguaje, que no solamente altera los cánones tradicionales de género y estilo, sino que rebasa su propia condición de ser lenguaje. Se puede hablar de una relación de duelo con respecto a la palabra, vinculada a la intuición que es el lenguaje lo que constituye al ser humano, pero que, a la vez, lo aliena y aísla (Lacan, 1975 [1953]).
} 
sino, también, aquélla del narrador y de la autora misma. Lo anterior indicará el camino para la puesta en debate de las formas narrativas tradicionales en general y de la posición del narrador mismo con respecto al lenguaje y la realidad. "He llegado finalmente a la nada. Y con la satisfacción de haber alcanzado en mí el mínimo de existencia, apenas la respiración indispensable, me hago libre. [...] Soy incómodo para mí... ¿Para mi qué? ¿Verdad? ¿Acaso tengo una verdad?" (Lispector, 1999: 68).

Mediante el devenir incierto de la escritura, ella se ve confrontada con los confines del lenguaje, ahí donde las palabras se fracturan y toda noción convencional de representación estalla. La ruptura de la noción tradicional de autor no solamente es la consecuencia teórico-conceptual de los presupuestos anteriormente aludidos, sino que se vuelve una experiencia, tal como testimonia el siguiente pasaje, que nos habla de la búsqueda realizada por el personaje del "Autor" en Un soplo de vida: "Me he vuelto una abstracción de mi mismo: soy un signo, simbolizo alguna cosa que existe más que yo" (Lispector, 1999: 66).

\section{UN SOPLO DE VIDA. LOS PERSONAJES Y SU AUTOR}

Clarice Lispector, en Un soplo de vida, pulsaciones (1999), finalizada en vísperas de su muerte, crea a dos personajes, los que, a su vez, se crean entre ellos: el personaje del "Autor" crea a otro personaje, "Ángela Pralini”, el cual posibilita el habla del "Autor". El texto entero se erige a partir de un diálogo entre ambos que, por momentos, se divide en dos monólogos que se unen y separan de manera intermitente. No se devela nada de orden biográfico o histórico con respecto a ellos, sólo se constituyen en un eterno presente, sin nada que los anteceda o preceda ${ }^{3}$.

Es así como el "Autor" afirma: "Yo, que aparezco en este libro, no soy yo. No es autobiográfico, vosotros no sabéis nada de mí. Nunca te he dicho y nunca te diré quién soy. Yo soy vosotros mismos" (Lispector, 1999: 20). En las líneas precedentes se cuestiona la pertinencia de remitir al autor como

\footnotetext{
${ }^{3}$ Esta propuesta, en la cual autor, personaje y un tercer actor -el lector- se confunden y entremezclan, pudiendo incluso formar uno solo, evoca la llamada "muerte del autor". Para Roland Barthes, otorgarle al texto una autoría y asignarle una única interpretación es imponerle un límite; el texto, por el contrario, sería un tejido de citas provenientes de diversos focos culturales, no de una sola experiencia individual. El sentido y unidad de una obra, por lo tanto, no reside en su origen o en su creador, sino que depende de las percepciones del receptor. "La escritura es ese lugar neutro, compuesto, oblicuo, al que va a parar nuestro sujeto, el blanco y negro por donde acaba por perderse toda identidad, comenzando por la propia identidad del cuerpo que escribe" (Barthes, 1994: 65).
} 
fuente última y primera del texto, en tanto dador de sentido de su propio texto. En lugar de adherir a esta lógica del autor, el texto de C. Lispector, en estrecha concordancia con Barthes (1994), sugiere que "el escritor nace a la vez que su texto, no está provisto de un ser que preceda o exceda su escritura, no es en absoluto el sujeto cuyo predicado sería el libro; no existe otro tiempo que el de la enunciación, y todo esto está escrito eternamente aqui y ahora" (68).

Este "nacer a la vez que el texto" implica, a su vez, que el personaje de Ángela Pralini, como supuesta creación dominada y engendrada por el $\mathrm{Au}$ tor, se escapa a éste - "Tuve que inventar un ser que fuese todo mío. Pero ocurre que ella está adquiriendo demasiada fuerza" (Lispector, 1999: 61)-, al punto que llega a definirse como "un escritor enmarañado y perdido" (Lispector, 1999: 61).

Es aquí donde conviene recordar que el campo literario no sólo está constituido por autores y obras sino que también por lectores y que, en analogía a lo señalado de entrada en relación al desplazamiento operado con respecto a la tradición psicobiográfica clásica, es el autor quien le da sentido a la actividad literaria. Evidentemente, la literatura es un proceso de producción, pero, asimismo, es un hecho innegable que el texto, una vez puesto en circulación, es recepcionado $-\mathrm{y}$ consumido- en espacios que difieren de su punto de elaboración. En otras palabras, no es posible excluir el acto receptivo en el origen de los textos. Es así como Ángela, el personaje creado por el "Autor", "está siempre a punto de hacerse" (Lispector, 1999: 62). La escritura se perfila como un proyecto inacabado, que sólo se completa en las infinitas lecturas y relecturas de otros. En este sentido, el texto literario es una estructura abierta, no fijada por completo, y es el lector quien viene a llenar los vacíos: "En el triángulo formado por autor, obra y público, este último no es sólo la parte pasiva, cadena de meras reacciones, sino que a su vez vuelve a constituir una energía formadora de historia. La vida histórica de la obra literaria no puede concebirse sin la participación de aquéllos a quienes va dirigida" (Jauss, 1976: 163).

Es por ello que el propio Autor se reconoce como proyecto - "Yo soy mi gran aventura: me arriesgo en todos los instantes" (Lispector, 1999: 62)-, como un devenir textual que, en palabras de Segre, se halla "en un estado de continua potencialidad. El texto es una materia atravesada por líneas escritas que están inertes hasta que se leen. El texto no empieza a significar, y a comunicar, hasta que interviene el lector" (1985: 371). Es sólo mediado por otro -Ángela Pralini, el lector- que el Autor y el texto que de él emana adquiere sentido. Advertimos, en este lugar, cierta afinidad con el mecanismo 
de significación, tal como se encuentra en Freud, un proceso que designa una modalidad de retranscripción o reinscripción, que ordena el material siempre a posteriori, nachträglich, après-coup, modificando su sentido constantemente en función de proyecto.

No obstante, las analogías con el psicoanálisis freudo-lacaniano, a pesar de las innegables diferencias, no terminan aquí, en el territorio metodológico, sino que pueden ser extendidas a la problemática que nos convoca, a saber, las relaciones entre la noción de autor en el texto de Clarice Lispector y el concepto psicoanalítico de sujeto.

\section{CONSTRUCCIÓN Y DECONSTRUCCIÓN DEL AUTOR: HACIA EL SUJETO PSICOANALÍTICO}

Se vuelve necesario, en este lugar, explicitar algunas de las relaciones entre una cierta concepción de autor y el concepto psicoanalítico de sujeto ${ }^{4}$.

En la actualidad, más allá de la polisemia y dispersión irreductibles del término, existe consenso al momento de considerar que el descentramiento psicoanalítico consiste en un desplazamiento del eje de la vida psíquica desde la conciencia al inconsciente. Lo inconsciente, en la medida en que es pensado como "aquella parte del discurso concreto en cuanto transindividual que falta a la disposición del sujeto para restablecer la continuidad de su discurso consciente" (Lacan, 1975 [1953]: 248) y, al mismo tiempo, se piensa como algo estructurado como el lenguaje, pudiendo definirse como el discurso de Otro, siendo el lenguaje la condición de su existencia y su única materialidad. Lacan (1959-60) plantea: "Es ante el Otro como sujeto de la palabra, en tanto que ella se articula primordialmente, es en relación a ese Otro, que el sujeto mismo se constituye como sujeto que habla. Nunca como sujeto primitivo del conocimiento, ni sujeto de los filósofos, sino el sujeto en tanto que se plantea como mirado por el Otro, como pudiendo responderle en el nombre de una tragedia común..." (148).

El sujeto que se asoma a través de las condensadas y enrevesadas líneas del texto de Lispector es justamente el sujeto en tanto parlêtre, habla(nte)ser,

\footnotetext{
${ }^{4}$ Entre las diferentes genealogías de la palabra "sujeto" quisiéramos destacar a una en particular, que apunta al siglo XVI, el en el cual dicha expresión habría sido adoptada del latín (Hentschel y Weydt, 2003). El verbo latín subicere, de cuyo participio perfecto pasivo (subiectum) habría sido formado el término; posee la significación de "colocar debajo", "subyacer", lo que convierte al sujeto en lo subyacente, lo que yace por debajo. Boethius empleo la palabra subiectum en su traducción de Aristóteles para la palabra griega hypokeimenon al latín ('quos praedicati suscipit dictionem') (Cardona, 1991). ¿Qué significa, no obstante, lo que yace debajo o aquel del que algo es enunciado?
} 
serhablante, sujeto de la palabra, alienado y sostenido por ella. Un sujeto en posición de desconocimiento y falta, en relación de asombro y perplejidad con respecto a lo que lo constituye y lo sobrepasa, que es, justamente, la palabra: "Ángela se cubre el rostro con las manos y llora por haber sido creada. La consuelo haciéndole entender que yo también padezco la vasta e informe melancolía de haber sido creado. Yo también obedezco a la persistencia de la vida. No es una elección: es una íntima orden de batalla. Y una vez que recibí el soplo de vida que hizo de mí un hombre, soplo en ti que te vuelves un alma. Tú no comienzas por el principio, comienzas por el medio" (27).

El sujeto del deseo, efecto de la inmersión en el lenguaje, es diferente, por lo tanto, del sujeto de la comprensión. Efecto del lenguaje, no es sin embargo un elemento de él: "ex-siste" (se mantiene afuera) al precio de una pérdida, pérdida que como tal no es una elección, sino más bien una orden de batalla.

El sujeto en cuestión repite la experiencia freudiana que "el yo no es el amo $\{$ Herr $\}$ en su propia casa” (Freud, 1917 [1916]: 135), en otras palabras, que somos desconocidos para nosotros mismos y que aquello que considerábamos como el centro de nuestro ser no es más que algo proveniente de afuera, algo sensible, equívoco y contingente. El yo, lejos de reducirse a una instancia monolítica consciente y transparente ante sí misma, será pensado como una composición estratificada, plural y heterogénea, de la cual mucho, sino acaso la parte elemental, es inconsciente. La denominada "subversión del sujeto cartesiano" acaso puede resumirse en el siguiente aforismo: "Pienso donde no soy, soy donde no pienso" (Lacan, 1966-67), estableciéndose así una división entre el sujeto de la conciencia y el sujeto del significante.

El sujeto que se desprende del texto de Lispector, en que tanto el Autor como los personajes no serán la fuente y origen último de sus palabras, testimonia dicha subversión: "Autor: lo peor es que soy viceversa y en zigzag. Soy no concluyente. Pero es necesario amarme como soy de forma involuntaria. Sólo me responsabilizo de lo que hay de voluntario en mí y que es muy poco" (Lispector, 1999: 124).

Se trataría entonces de un sujeto que duda de su propio ser, que descarta la ontología de la existencia, un sujeto que se sabe sobredeterminado, donde el yo, siguiendo a Freud, no será más que un epifenómeno ilusional de todo ese universo simbólico mayor que lo determina: "Autor: mi no yo es magnífico y me supera. No obstante, ella me es yo" (Lispector, 1999: 35).

En la medida en que plantea que el yo no sabe nada acerca de los deseos del sujeto (Lacan, 1975), no sólo el Autor dudará de su propia identidad, 
sino también el personaje creado por éste: ambos oscilan en una posición fantasmática con respecto a ellos mismos. Una vez destronado el autor, tal como sostiene Barthes (1994), será el lenguaje el que habla, el que actúa y performa; el autor se suprime en beneficio de la escritura, devolviéndole su sitio al lector, pues "el autor nunca es nada más que el que escribe, del mismo modo que yo no es otra cosa sino el que dice yo: el lenguaje conoce un 'sujeto', no una 'persona', y ese sujeto, vacío excepto en la propia enunciación, que es la que lo define, es suficiente para conseguir que el lenguaje se 'mantenga en pie"' (67- 68).

El autor, en ese sentido, no puede conocerse, no puede saberse positivamente de una manera absoluta, ya que el eje de su existencia le es inaccesible. El sujeto-autor aparece expropiado de su intimidad, razón por la cual Lacan esgrime el neologismo de extimidad ${ }^{5}$, de un afuera localizado en el centro mismo del sujeto. El lenguaje, contrariamente a lo que sostienen los defensores de las teorías nominalistas, no es un útil del que el hombre dispondría según su voluntad, sino que le es radicalmente exterior a los seres hablantes, anterior a ellos, y de su entrecruzamiento con el cuerpo queda un sedimento de naturaleza simbólica, lo inconsciente. Con respecto a esta "excentricidad", a este desconocimiento que se va marcando por y en la palabra, el Autor dice: “¿Hasta dónde soy yo y en dónde comienzo a ser Ángela? ¿Somos frutos del mismo árbol? No. Ángela es todo lo que yo querría ser y no he sido (...) Ángela es mi vértigo. Ángela es mi reverberación y, siendo emanación mía, ella es yo. Yo, el autor: el incógnito. Que yo sea yo es pura coincidencia. Ángela parece algo íntimo que se ha exteriorizado" (Lispector, 1999: 28). El sujeto no es él mismo, es otra cosa, "Je est un autre", como repite Rimbaud en sus Lettres du Voyant. "Yo, el autor: el incógnito" (Lispector, 1999: 33). Es el propio Autor el que se duda a sí mismo, el que intenta validarse a través de la creación de su personaje y finalmente se siente superado y se desvanece.

Para el psicoanálisis, la enunciación, opuesta al enunciado, se vincula con los procesos de producción de sentido a partir de una discontinuidad estructural entre el sujeto de la enunciación y el sujeto del enunciado. Según Albano (2005) la enunciación es aquello por lo cual el sujeto "es hablado"

\footnotetext{
${ }^{5}$ Esta expresión es un neologismo, introducido por Lacan y retomado por J. A. Miller, construido sobre el término "intimidad". El vocablo sugiere una salida a las nociones de interior-exterior, mundo interno-mundo externo, las que, según el psicoanálisis lacaniano y la subversión de la topología clásica, no tienen sentido más que en un nivel que cabría designar como puramente imaginario. "Extimidad", en ese sentido, permite establecer que lo mas interno, lo mas íntimo, lo más propio, se encuentra en el exterior al modo de un cuerpo extraño, que reconoce una ruptura constitutiva de la intimidad.
} 
y el enunciado es lo que el sujeto "habla" en tanto tal, mediante el yo que lo introduce en un discurso. La enunciación no puede ser "dicha" por el enunciado, en tanto condición de posibilidad de éste, por lo mismo, no existe recubrimiento posible entre enunciado y enunciación, por cuanto en esta discontinuidad opera pues la división subjetiva. En efecto, la división subjetiva se constituye por la división que se produce entre el enunciado y la enunciación.

De acuerdo con esto, a propósito del intento por establecer un diálogo entre Autor y Ángela, se irá evidenciando la imposibilidad de producirlo, en tanto ambos se saben ficticios, sobredeterminados. En su escritura no elabora un discurso explícito de la pérdida, pero la produce como efecto de lectura: el relato está lleno de huecos, espacios vacantes de sentido, de fugas: inventa palabras, cambia los tiempos verbales, usa indiscriminadamente los signos de puntuación e incluso deja una página en blanco en la mitad de un capítulo. Esta vaciedad se acrecienta en la creación de los personajes: a ambos les falta algo que no saben nombrar y que parecieran incapaces de producir para sí. Buscan algo y ese algo buscado, en tanto objeto de deseo es por lo tanto irrecuperable, en tanto la pérdida no puede ser evocada: "Autor: Cosas difíciles de ser plenamente vividas, pues ¿̨dónde está el centro único de la pulpa de la fruta para que yo muerda? Disparar finalmente la flecha. Pero, si no llego a alcanzar el blanco exacto, pereceré. Es por miedo a eso por lo que no me atrevo. ¿Morir por causa de una palabra? [...] Lo que sostiene es la necesidad. La necesidad me hace crear un futuro. Porque el deseo es algo primitivo, grave, que empuja" (Lispector, 1999: 142).

En un principio, el autor construye a Ángela como un intento de reconocerse en ella, como un intento de respuesta, que lo defina y obture: "Autor: Ángela...querría que en mi modo de fijarte para mí mismo nada tuviese recortes y definiciones: así todo se entrelazaría en un movimiento circular" (Lispector, 1999: 27). Sin embargo, en la medida en que progresa dicho intento de espejeamiento complementario por la vía de la escritura, se va acentuando, cada vez más, la imposibilidad radical de este intento, lo que incidirá en que se asome la angustia que, por momentos, exhiben los personajes, en tanto las respuestas a sus interrogantes -¿Quién soy? ¿Qué quiere el Otro de mí? - no provendrán del Otro y que en esa relación imaginaria hay un universo simbólico mayor, que los trasciende y los determina desde otro lugar.

"Autor: Ángela no sabe que es personaje y, quién sabe, tal vez yo sea también personaje de mí mismo. ¿Sentirá Ángela que es un personaje? Porque en lo que a mí respecta, siento de vez en cuando que soy el personaje de 
alguien. Es incómodo ser dos: yo para mí y yo para los otros. Ángela es mi necesidad" (Lispector, 1999: 28).

De esta manera, se revela un juego constante entre la lucha por la autodefinición y la imposibilidad de conseguirlo, dando lugar a un movimiento de oscilación que se revela en el siguiente fragmento: "Autor: Siempre quise alcanzar un estado de paz y de no-lucha. Pensaba que era el estado ideal. Pero ocurre que... ¿qué soy yo sin mi lucha? No, no sé tener paz. Mi pregunta es del tamaño del Universo. Me queda sin embargo un temor: no encontrar, si busco [...] soy una pregunta insistente que no llega a oír una respuesta. Nunca nadie me ha respondido. Intento en vano encontrar en Ángela la respuesta. Aguzo el oído para escuchar la respuesta. Como si mi pregunta gritada me diese algo más que el eco de la pregunta" (Lispector, 1999: 140). Podemos constatar, entonces, en el autor un intento de identificación imaginaria, una necesidad de estar, a través de la mirada del otro, "todo entero, allí afuera", donde en el dominio de la imagen arranca la alienación originaria del sujeto.

Sin embargo, en este intento identificatorio, irá evidenciándose, en las palabras del Autor, la irrupción de otro discurso, del discurso del Otro. Hace la experiencia de un discurso, asumido imaginariamente como propio, pero que trastabilla y finalmente lo supera, sublevándose. "Me pone tenso esa especie de relajamiento en que Ángela vive. No consigo alcanzarla, ora huye de mí, ora está al alcance de mi mano; y cuando pienso que está al alcance, ella, intrínseca, se subleva" (Lispector, 1999: 127).

De este modo, parafraseando a Recalcati (2006), comenzará una progresiva reducción de las vestiduras yoicas, desarticulándose de su dominio narcisístico, que finalizará en la conducción del sujeto hacia la asunción de su propio ser en cuanto ser marcado por la acción del Otro, en tanto determinado por el significante, como un sujeto que emerge como resultado del atravesamiento del lenguaje, es decir, por el Otro, y su consecuente alienación producida por éste.

Se insinúa, como efecto de escritura, la posibilidad de devenir a través del texto, de convertir la palabra ajena en propia, abriendo ciertas posibilidades de desplazamiento metonímico. En el caso de Un soplo, tanto el Autor como el personaje serán hablados por el Otro, pudiendo forjar algún tipo de subjetividad a través del asalto que las palabras producen en ellos: "Lo incomunicable de uno a uno mismo es la gran vorágine de la nada. Si no encuentro un modo de hablarme a mí mismo, la palabra me sofoca y me atraviesa la gargantea como una piedra. Quiero tener acceso a mi mismo en el momento que quiera" (Lispector, 1999: 152). 
Ángela, como personaje, como receptora de su propia creación, va a su vez "leyendo" las palabras de su autor. Se aleja de ellas, se acerca, no las entiende. El autor, a su vez, pretende darse una voz a través de Ángela, intentando ser otro mediante esa voz femenina. Pero, ¿qué sucede? La lectura de uno y de otro se trastoca; la respuesta no proviene de ellos y, al parecer, tampoco de Clarice, en tanto dice: "Escribir existe por sí mismo? No, es sólo el reflejo de una cosa que pregunta [...] Cuando alguien escribe o pinta o canta transgrede una ley" (Lispector, 1999: 60).

La palabra, en tanto "asesinato de la cosa" (Lacan, 1975 [1953]: 307), afecta al cuerpo, lo desvitaliza; ganar un lugar como sujeto en el campo del significante es perder el ser de la vida natural. Atravesado por el significante, el hombre paga un precio por hablar. Así, lo inconsciente no es -al menos solamente- un fondo de desconocimiento, lejano y pasivo y, en tanto inconsciente freudiano, "no tiene nada que ver con las formas llamadas del inconsciente que le han precedido [...] Tropiezo, fallo, fisura... -la sorpresa, eso por lo que el sujeto se siente rebasado, por lo que halla a la vez más y menos de lo que esperaba" (Lacan, 1986 [1964]: 36-37).

El Autor de la obra de Lispector establece una relación compleja al lenguaje, hablando, intentando decirse y, al mismo tiempo, fracasando en el intento. Al habitar en el lenguaje y estar anclado a él y sus efectos, tanto el Autor como Ángela acusan una carencia fundamental, que remite a que en el Otro, "el tesoro de los significantes" (Lacan, 1987 [1960]: 796), falta un significante. El fracaso recién aludido guarda relación con el hecho de que no somos capaces de decir toda la verdad, ya que "decirla toda es materialmente imposible: faltan las palabras" (Lacan, 1977: 117). "Mientras viva", dice el Autor, "tendré de vez en cuando la casi-no-sensación de lo que no se puede nombrar" (Lispector, 1999: 141).

La casi-no-sensación aludida desmiente la idea de un sujeto autónomo, fuente y origen del discurso, que puede expresarse recurriendo a la infinita variabilidad morfológica, fonológica, sintáctica y semántica que el sistema de la lengua pone a su disposición. De este modo, en Un soplo de vida los personajes oscilarán entre la identificación imaginaria, intentando recubrir la falta en el Otro así como el desgarro de este intento. El Autor no logra ser el Amo de Ángela, Ángela, por su parte, va tomando vida en el texto más allá de su productor. "Lo que Ángela desconoce", dice el Autor, "la ilumina y la domina más que aquello que conoce. En realidad, no sabe qué hacer con lo que conoce" (Lispector, 1999: 134).

La imposibilidad constatada se relaciona con el hecho que "se necesita la mediación de un tercer personaje que realice respecto del sujeto el elemento 
trascendente, gracias a la cual su relación con el objeto puede sostenerse a cierta distancia” (Lacan, 1986 [1964]: 40). ¿Quién podría ser el tercer personaje en el texto de Lispector? El diálogo entre Autor y Ángela deviene imposible. La palabra habla mediante ellos. Lispector, como autora de ambos, podría ser ese tercer personaje, sin embargo, su escritura devela que ella misma está sujetada, en tanto se deja entrever, como fue mencionado anteriormente, que duda de la existencia del propio escritor, dejando abierto, así, el paso al lector.

Lo que falta en el Otro es un significante. No hay Otro del Otro, por lo que ese intento de recubrir la falla será siempre una ilusión.

\section{CONCEPCIONES DE SUJETO. RELACIONES POSIBLES ENTRE PSICOANÁLISIS Y LITERATURA}

Tanto la clínica psicoanalítica como la literatura y la poética vinculan al sujeto a un universo simbólico consistente y plantean la división subjetiva como un correlato necesario de un universo simbólico incompleto. La concepción de sujeto que es posible formular a través de la lectura de Un soplo de vida se manifestará a través de la estructuración misma del texto, así como en la relación entre ambos personajes -Autor y Ángela. Dicha manifestación acontece, de preferencia, a través de un particular "uso del lenguaje”, generado a través de un continuo diálogo -o, mejor dicho, la continua imposibilidad de diálogo- entre ambos. "¿Estoy hablando yo o está hablando Ángela? La vida real es sólo simbólica: se refiere a alguna otra cosa. Yo no existiría si no hubiese palabras" (Lispector, 1999: 79).

El Autor quiere asir una subjetividad, por y para ello escribe. Confiesa querer "Salvar la vida de alguien" (Lispector, 1999: 9) a través de la escritura; sin embargo, el movimiento continuo cierra la posibilidad de unificación de la conciencia y -paradójicamente- le abre paso a la existencia de una subjetividad otra. La subjetividad que se va configurando, la escritura mediante, remite a un sujeto en falta, deseante, siempre por advenir. Deseo de sujeto, sometido a la diferencia significante, lógica que difiere, pospone y aplaza el soñado acceso al objeto -en este caso, al sujeto- e instituye una imborrable diferencia entre lo hallado y lo anhelado.

El personaje Ángela -a quien el Autor construye, en un principio, como un objeto utilitario, que le permitirá posicionarse frente al mundo- poco a poco pasará de ser una herramienta para la satisfacción del deseo del Otro a constituirse como un objeto inalcanzable, que el Autor inútilmente intenta- 
rá asir con sus palabras. Ángela terminará así por escaparse en tanto creación del Autor y se creará un constante interjuego en un ir y venir entre las palabras de Ángela y el Autor, donde cada uno se verá atravesado a su vez por la presencia y mirada del otro, así como del universo simbólico mayor que los determina: "Me sorprendo y al mismo tiempo desconfío de tanto que me es dado. Y mañana tendré un nuevo hoy. Hay algo doloroso y tajante en vivir el hoy. El paroxismo de la nota más fina y alta de un violín insistente. Pero está el hábito y el hábito anestesia" (Lispector, 1999: 14).

A pesar de dicho hábito, que representa la captación del sujeto en el registro de lo imaginario, recurso con que cuenta para aferrarse a la realidad y hacerla continua, habitable, consistente, su imposibilidad golpea con fuerza. Se deduce aquel esfuerzo del individuo por sostenerse, afirmarse en la creencia de la totalidad y cronicidad, sin embargo, el sujeto emerge, introduciendo la dimensión de lo imposible en aquella ilusión: "Finjo que soy una determinada persona pero en realidad no soy nada" (Lispector, 1999: 38). Este no ser nada, como el vacío que se presentifica a través de la imposibilidad de la palabra, haciendo así surgir la angustia de los personajes y su insistente relación a la muerte en tanto enfrentamiento con el vacío y la imposibilidad de "decirlo todo": "La muerte queda más allá de la medida del hombre. No tengo conocimiento de su lenguaje mudo. Me parece que la muerte no es un hecho, es una sensación que ya debería estar conmigo. Pero aún no la he alcanzado" (Lispector, 1999: 145).

En Lispector, el lenguaje es un anzuelo para encontrar la palabra en lo no-conocido, lo no-nombrable. Específicamente, propone escribir, "lanzando un anzuelo" (Lispector, 1999: 12), evidenciando un sentimiento de fracaso del lenguaje, pues se trata de una lucha agónica ${ }^{6}$ con las palabras. En su obra hay pocas frases que comuniquen, se habla sin entenderse, la lengua es insuficiente para expresar el pensamiento. Al invertir la fórmula Saussureana "Significado/Significante", Lacan pondrá el acento en la primacía del significante; la barra que separa a ambos elementos es resistente a la significación, imposibilitando una relación univoca. De esta manera, la significación nunca puede cerrarse, estando en constante desplazamiento, eternamente suspendida en la cadena significante.

La escritura de Lispector, en cierto sentido, bordea aquello, cuya formu-

\footnotetext{
${ }^{6}$ Michel Foucault (1991), al momento de describir la relación de la libertad con el poder, en vez de caracterizarla como antagónica, prefiere recuperar el término griego agon (ó́óv), con tal de describir a dichas relaciones como relaciones de incitación permanente, provocación incesante, acicate mutuo. Estas relaciones, por consiguiente, han de ser pensadas como contiendas, desafíos o disputas irreducibles, que no apuntan a ser resueltas.
} 
lación resulta inalcanzable, que no puede ser completamente simbolizado en la palabra y la escritura y que, por consiguiente, en tanto el sujeto lucha por arrancar la palabra que lo nombre, "no cesa de no escribirse" (Lacan, 1985 [1972-1973]). En su obra, lenguaje e identidad son conocidos como construcción, como fórmulas. La autora extrae, pues, las palabras de sus vínculos semánticos. Ellas no sirven para designar ni denotar la realidad. Se ha perdido la confianza en el lenguaje, se ha reconocido la insuficiencia de éste a través de una escritura que la propia autora designa como "tortuosa, inconclusa y oscilante" (Lispector, 2007: 12). Afirma: "Sí. Siento lo que será siempre inaccesible para mí. Sí. Pero lo sé todo, todo lo que sé sin realmente saber no tiene sinónimo en el mundo del habla, pero me enriquece y me justifica. Aunque perdí la palabra porque intenté decirla” (Lispector, 1999: 55).

Por muy creador que sea el acto escritural, incluso la más precisa de las palabras jamás podrá evitar la aparición de otra, y de otra, cuya concatenación desviará al sujeto del camino emprendido, ya que una vez dicha la palabra, el camino hacia la satisfacción se vuelve a abrir. La obra bordeará lo indecible, lo irrepresentable, sitiándolo en su caso con la palabra: "Pero al mismo tiempo todo es tan fugaz. Siempre fui e inmediatamente dejaba de ser" (Lispector, 1999: 33). En consecuencia, a través de la palabra se alcanza un umbral, un límite o una frontera y, de inmediato, como consecuencia de la lógica del desplazamiento, se abre una serie al infinito.

Pareciera ser que en este lugar nos topamos con un singular objeto, el cual, al carecer de su correspondiente representación, no se inscribe en el tejido simbólico y se arraiga en su más allá, quedando vinculado a la dimensión de la falta del significante en el otro. En estricto rigor, no se trata de un objeto existente, sino de una ausencia, de un vacío, cuya eficiencia reside en el hecho de actuar como causa del deseo. Por un lado, impresiona como un resto, que cae de la constitución del sujeto, a partir de la cual éste pasa a existir simbólicamente, mientras que, por el otro, hay algo que no termina de ser incluido en la simbolización y, por lo mismo, no es imaginarizable -se trata de un Real residual, y que resulta de la operación de constitución del sujeto en el campo del Otro del significante.

Por momentos, el Autor buscará aquello que se pierde en la constitución subjetiva, aquello no imaginarizable: "Soy demasiado nostálgica, parece que he perdido algo, no se sabe ni dónde ni cuándo" (Lispector, 1999: 68). Empero, lo real se presenta ante los protagonistas como un corte que los enfrenta y no los deja nombrar. "Sí, quiero la palabra última, que también es tan primera que ya se confunde con la parte intangible de lo real" (Lispector, 1999: 89). 
Así, la función de la palabra en la obra de Lispector consiste en liberar al sujeto de todos los vínculos de coherencia que amarran la palabra a cierto rigor exigido por la coherencia discursiva, tras la cual, el yo resiste la emergencia de la palabra plena. Así, las amarras que retienen la palabra al servicio de las identificaciones del yo, una vez liberadas, confrontan al sujeto con un punto de verdad, que presenta algunas asombrosas analogías con el concepto de cura (Sorge) en la clínica psicoanalítica: "Quiero llegar sobre todo a asombrarme de mí mismo por lo que escribo. Ser cogido por sorpresa: estremecerme ante lo que nunca antes había llegado a decir" (Lispector, 1999: 67).

El Autor anónimo dice en algún momento: "Yo pido. ¿Qué pido? Esto: la posibilidad de pedir eternamente [...] fuera de mí soy Ángela. Dentro de mí soy anónimo. Vivir exige esa audacia” (Lispector, 1999: 39). ¿A qué audacia se refiere? A la posibilidad, podríamos conjeturar, de pedir eternamente, es decir, de sostener su deseo en tanto la palabra absoluta, que clausurará la apertura del deseo, no adviene. Este oscilar, esta interrogante continua con respecto al lenguaje y su imposibilidad de ejercer una palabra plena y concluyente, se revela en las últimas y desgarradoras líneas del texto: "Autor: Por mi parte, estoy, si. Yo...yo.... no puedo acabar. Creo que..." (Lispector, 1999: 154).

\section{DISCUSIÓN}

"Yo...yo.... no puedo acabar. Creo que..." Las últimas palabras del texto de Clarice Lispector evocan la falta de respuesta, la castración y la muerte; en suma, el límite último e infranqueable, el que no podría sino manifestarse al modo de una fractura, el desgarro constituyente del sujeto fragmentado inmerso en el lenguaje.

La lectura de Un soplo de vida, a su vez, constituye un texto que es diálogo e imposibilidad del mismo, que nunca se completa y está siempre en un continuo hacerse, al igual que el sujeto que narra. Lo narrado, así, no tiene principio ni fin, es un continuo hacerse desde el momento inicial de ejecución: "Nacido en un momento del tiempo, el texto puede volver a ser propuesto en el transcurso del tiempo" (Segre, 1985: 371).

Iniciamos nuestra lectura planteando, a través de las palabras de otro, que no se interpreta al artista ni al psiquismo de éste a través de su obra, acaso estableciendo cierta relación de continuidad o de correspondencia causal o lineal entre ambos. Más bien, dijimos, es el objeto de arte el que 
interpreta a quien lo contempla, funcionando al modo de objeto que causa su deseo, primero, por capturar su mirada, segundo, y ante todo, porque le hace hablar.

Dicho deseo jamás será satisfecho, principalmente, por la doble relación que el sujeto mantiene con el lenguaje. Doble en el sentido de que, por un lado, es hablado por el lenguaje y, por el otro, habla. Y mientras hable, mientras esté inmerso en un mundo simbólico, donde las palabras no se corresponden biunívocamente con un significado, jamás logrará la plena satisfacción del deseo, ya que de ahí a ésta se extiende un campo vasto e infinito. $Y$ ese campo imperecedero es el que relacionamos con las líneas finales del texto, que dejan a éste abierto e inacabado: "Creo que..." manifiesta una duda, un no saber, un creer que se duda a sí mismo. Los puntos suspensivos al final de la novela impresionan como el signo de un discurso hilvanado a retazos, apenas acabado, y un habla casi balbuceante, que no puede registrar la palabra precisa en ese espacio que se encuentra entre el sujeto y la cosa. Señalan, con su trazo, la ausencia que, sin embargo, se encuentra ya en el propio texto, puesto que la presencia irremediablemente evoca y alude a lo ausente.

Podría decirse, entonces, que Lispector, a través del proceso de escritura, se deja morir como autora, desprendiéndose, de este modo, que la palabra última, la palabra absoluta, no la tiene el Autor, no la tiene el personaje, no la tiene el lector. A través de la escritura, entonces, y de la compleja relación al lenguaje que establecen los personajes, podría decirse, tal como menciona el Autor, que escribir no existe por sí mismo, que "es sólo el reflejo de una cosa que pregunta" (Lispector, 1999: 60) y que la palabra se pierde "justo porque intenté decirla" (Lispector, 1999: 55). Así, desde una (in)conciencia radical de la incomunicación y del fracaso de la expresión conceptual para penetrar en el mundo de las vivencias, Lispector trabaja sobre lo indecible desde la escritura, jugando así con los límites de la palabra, ahí donde éstas se agrietan, se resquebrajan, diseminando sus fragmentos al infinito.

\section{REFERENCIAS}

Albano, Sergio. 2005. Glosario de términos lacanianos. Buenos Aires: Quadrata.

Baron, Samuel H. y Pletsch, Carl (ed.). 1985. Introspection in Biography: The Biographer's Quest for Self-Awareness. Hillsdale, N.J.: Analytic Press. Barthes, Roland. 1994. "La muerte del autor". En R. Barthes, El susurro 
del lenguaje: más allá de la palabra y la escucha (pp. 65-68). Barcelona: Paidós.

Cardona, Giorgio R. 1991. Diccionario de lingüistica. Barcelona: Ariel.

Ciardiello, Jean A. 1985. "Beethoven: modern analytic views of the man and his music". Psychoanal. Rev., 72, pp. 129-147.

Erikson, Erik H. 1958. Young-Man Luther: A Study in Psychoanalysis and History. New York: Norton.

Erikson, Erik H. 1975. Life history and the historical moment. New York: Norton.

Freud, Sigmund. 1917 [1916]. "Conferencias de Introducción al psicoanálisis. El estado neurótico común”. En Obras Completas, tomo XVI (pp. 344-356), Buenos Aires: Amorrortu, 1985.

Freud, Sigmund. 1919. "Das Unheimliche". En Gesammelte Werke, tomo XII (pp. 227-278), Frankfurt a. M.: Fischer, 1999.

Freud, Sigmund. 1933 [1932]. "Neue Folge der Vorlesungen zur Einführung in die Psychoanalyse. Die Zerlegung der psychischen Persönlichkeit”. En Gesammelte Werke, tomo XV (pp. 62-86). Frankfurt a. M.: Fischer, 1999.

Foucault, Michel. 1991. Estrategias de poder. Obras esenciales, Vol. II. Barcelona: Paidós.

Hentschel, Elke \& Weydt, Harald. 2003. Handbuch der deutschen Grammatik. $3^{\text {a }}$ edición. Berlin/New York: de Gruyter.

Jauss, Hans Robert. 1976. La historia de la literatura como provocación de la ciencia literaria. Barcelona: Crítica.

Lacan, Jacques. 1959-60. El Seminario. Libro 6. El deseo y su interpretación. Inédito.

Lacan, Jacques. 1966-67. El Seminario. Libro 14. La lógica del fantasma. Inédito.

Lacan, Jacques. 1975 [1953]. "Función y campo de la palabra y el lenguaje en psicoanálisis”. Escritos 1, pp. 227-310. México: Siglo XX.

Lacan, Jacques. 1977. Radiofonía y televisión. Barcelona: Anagrama.

Lacan, Jacques. 1985 [1972-1973]. El Seminario. Libro 20. Aun. Buenos Aires: Paidós.

Lacan, Jacques. 1986 [1964]. El Seminario. Libro 11. Los cuatro conceptos fundamentales del psicoanálisis. Buenos Aires: Paidós.

Lacan, Jacques. 1987 [1960]. "Subversión del sujeto y dialéctica del deseo en el inconsciente freudiano". Escritos 2, México: Siglo XXI.

Lispector, Clarice. 1999. Un soplo de vida, pulsaciones. Madrid: Siruela.

Lispector, Clarice. 2007. Para no olvidar. Madrid: Siruela. 
Ponce, Xavier G. 2006. "Entre náufragos: notas sobre fotografía, arte y psicoanálisis”. En Recalcati, M. Las tres estéticas de Lacan, pp. 137-147. Buenos Aires: Del cifrado.

Recalcati, Massimo. 2006. Las tres estéticas de Lacan. Buenos Aires: Del cifrado.

Sarlo, Beatriz. 1985. Crítica de la lectura: ¿un nuevo canon de lectura? Buenos Aires: Punto de Vista.

Segre, Cesare. 1985. Principios de análisis del texto literario. Barcelona: Crítica.

Vattimo, Gianni. 1990. La sociedad transparente. Barcelona: Paidós.

Vattimo, Gianni. 1994. El fin de la modernidad: Nibilismo y hermenéutica en la cultura posmoderna. Barcelona: Gedisa. 